Kidney

Blood Pressure

Research

\title{
31st Congress of the Czech Society of Nephrology
}

June 22-24, 2006, Hradec Králové

\section{Selected Abstracts}

Guest Editors

I. Rychlík, Prague

S. Dusilová Sulková, Hradec Králové

\section{Contents}

Oral Presentations

Abstracts $01-025$

Abstracts P26-P28

Author Index

386 


\section{Oral Presentations}

01

\section{The Role of Angiotensin-(1-7) in the Pathophysiology of Hypertension in 'two- kidney, one-clip' Goldblatt Hypertensive Rats}

\author{
L. Cervenka, M. Bürgelová, M. Thumová, L. Kopkan, \\ V. Teplan, I. Vaněčková \\ IKEM, Prague
}

Introduction: There is growing evidence that angiotensin-(1-7) (ANG 1-7), a newly discovered component of the renin-angiotensin complex, has vasodilatory and natriuretic properties and thus it could be the substance compensating for pathophysiologic effects of angiotensin II (ANG II). Aim of the Study: To assess the role of ANG 1-7 in the patophysiology and chronic blockade of ANG on renal function and the development of experimental renovascular hypertension. Methods: The model of two-kidney, one-clip (2K1C) Goldblatt hypertension (i.e. the model, where one renal artery is clipped) was used as the model of renovascular hypertension. ANG 1-7 was infused chronically by osmotic minipumps implanted subcutaneously and receptor antagonist of ANG 1-7 was administered via the same route. Blood pressure (BP) was monitored telemetrically in vigilant animals. Clearance studies to assess renal functions were performed in the animals at the end of the study (28th day after clipping). The index of left heart chamber weight vs. body weight was used to assess heart hypertrophy. Results: Chronic infusion of ANG 1-7 did not diminish the development of hypertension in $2 \mathrm{~K} 1 \mathrm{C}$ rats and renal functions and heart hypertrophy were not influenced as well. On the other hand chronic blockade of ANG 1-7 accelerated the development of hypertension in $2 \mathrm{~K} 1 \mathrm{C}$ rats. Moreover, chronic blockade of ANG 1-7 caused significant decrease of kidney plasma flow in contralateral kidney comparing with control $2 \mathrm{~K} 1 \mathrm{C}$ rats and accelerated development of heart hypertrophy. Conclusions: It can be inferred from our results that endogenous ANG 1-7 diminishes development of hypertension in a significant way and has also a significant role in the regulation of renal function in $2 \mathrm{~K} 1 \mathrm{C}$ Goldblatt rats. These results support the hypothesis that ANG 1-7 acts as a physiological endogenous antagonist of ANG II in this model of renovascular hypertension.
02

\section{Renal Activity of RHOA in Experimental Diabetes Mellitus (DM)}

\author{
J. Ždychová1, A. Lodererová2, D. Lecian², J. Veselá1, \\ R. Komers ${ }^{1}$ \\ ${ }^{1}$ Centre of diabetology IKEM, ${ }^{2}$ KN IKEM, ${ }^{3}$ PKTP IKEM, Prague
}

Introduction: RhoA belongs to the group of Ras G-proteins taking part in post-receptor signalling of membrane receptors for growth factors, cytokines, integrins and vasoactive hormones. Activation of RhoA is dependent on binding with GTP and translocation to cell membrane. Activation of RhoA is linked to growth signalling, cytoskeleton reorganization, and cell contractility and has a role in the pathophysiology of atherosclerosis, hypertension and non-diabetic glomerulosclerosis. However, the effect of DM and its treatment on renal RhoA has not been studied yet. Methods: The expression of RhoA was measured by western blot in membrane and cytosolic fractions of homogenates of renal cortex of streptozotocin rats $(60 \mathrm{mg} / \mathrm{kg})$ with the duration of DM of 4 weeks and various level of metabolic compensation: severe hyperglycaemia (HG) without insulin treatment (DM-S), moderate HG (4 U of insulin/day, DM-M) and tight compensation of DM (12 U/day, DM-I). Renal localization of RhoA was assessed by immunohistochemistry. The results of DM rats were compared with non-diabetic controls (C) of the same age. To assess the effect of insulin on RhoA activation were $\mathrm{C}$ animals compared with non-diabetic animals treated with $6 \mathrm{U}$ of insulin (C-I). Results: Membrane expression of RhoA was increased in all DM groups $(+50-90 \%, \mathrm{p}<0.01$ vs. C). Cytosolic depletion of RhoA was observed only in DM-S $(-35 \%, \mathrm{p}<0.01$ vs. C). Nevertheless, the membrane/ cytosol fraction ratio of RhoA, studied as the main index of RhoA activation was increased in all groups of DM rats (DM-S $+767 \%$, DM-M $+654 \%$, DM-I $+491 \%, p<0.01$ vs. C). Similarly to DM, C-I showed significant membrane translocation of RhoA (+ 230\%). The highest RhoA immunoreactivity was observed in podocytes. Conclusion: Early phases of experimental DM nephropathy are connected with RhoA activation, which is not significantly influenced by improved metabolic compensation, most likely as the result of independent effect of insulin. The localization of RhoA points to possible contribution to the development of proteinuria and GS in DM.

Supported by MZO 00023001.

\begin{tabular}{ll}
\hline KARGER & (C) 2006 S. Karger AG, Basel \\
Fax +4161306 1234 & $1420-4096 / 06 / 0296-0374 / \$ 23.50$ \\
$\begin{array}{l}\text { E-Mail karger@karger.ch } \\
\text { www.karger.com }\end{array}$ & $\begin{array}{l}\text { Accessible online at: } \\
\text { www.karger.com/journals/kbr }\end{array}$
\end{tabular}




\section{3}

\section{Coronary Calcification (CC) Correlates with Bone Mineral Density (BMD) in Chronic Hemodialysis (HD) Patients}

\author{
J. Mareš ${ }^{1}$, K. Ohlídalová2, S. Opatrná1, J. Ferda², \\ K. Opatrný Jr. ${ }^{1}$, B. Kreuzberg \\ ${ }^{1} 1$ st Medical Department, Faculty Hospital, \\ ${ }^{2}$ Department of Radiodiagnostics, Faculty Hospital, Plzeň
}

Introduction: Atherosclerosis and vascular calcification are the main cause of high mortality in HD patients. Bone disease with increased risk of fractures is another important factor. The key role in both conditions is played by calcium phosphate metabolism impairment. Methods: $72 \mathrm{HD}$ patients, CT with BMD measurements in lumbar spine, Agatson CC score (SCC); control groups without kidney disease (SCC measured); 67 patients with ischemic heart disease (CHD), 93 patients with diabetes, results expressed as median and range; statistical comparisons with rank sum test. Results: Total BMD was 87 (227) mg calcium hydroxyapatite per $\mathrm{ml}$ of bone tissue $(\mathrm{CAHA} / \mathrm{ml})$ and corresponding T-score -2.9 (8.6). Vertebral fracture was found in 15 patients. Patients with fractures had higher serum calcium: 2.39 (0.37), $2.27(0.7) \mathrm{mmol} / \mathrm{l}(\mathrm{p}=0.008$ and lower BMD, cortical: 195 (100), $254(394) \mathrm{mg} \mathrm{CaHA} / \mathrm{ml}(\mathrm{p}<0.001)$ and trabecular 72 (69), 93 (229) $\mathrm{mg} \mathrm{CaHA} / \mathrm{ml}(\mathrm{p}=0.009)$. T-score was -3.3 (3.3), -2.7 (8.6), $\mathrm{p}=0.048$. Both groups did not differ in age. T-score lower than 2.5 was found in 47 patients. These patients had lower SCC than the group with T-score higher than -2.5: 667 $(10,240), 1,630(7,703)$ Agatson units (AU), $p=0.016$, in spite of lower age in the second group. HD patients with IHD history had higher SCC than patients without CHD: 1,657 (10,240), $442(6,965)$ $\mathrm{AU}, \mathrm{p}<0.001$. Both groups were not different in age. HD patients with CHD had Z-score and cortical BMD higher than patients without CHD: 0.26 (7), -0.5 (5.1), p = 0.025 and 276 (383), 232 (150), $\mathrm{p}=0.028$. SCC was $829(10,240) \mathrm{AU}$ in HD patients, $365(4,199) \mathrm{AU}$ in patients with CHD without kidney disease, and $74(2,746)$ in diabetics without kidney disease ( $p<0.001$, ANOVA). Conclusion: Advanced bone demineralization and massive $\mathrm{CC}$ were found in HD patients. Patients with vertebral fractures had lower BMD. History of CHD predicted increased SCC in HD patients. A straight correlation was found between BMD and CC. SCC was higher in HD patients than in control groups.

\section{4 \\ Physiological Variability of Hemodialysis Vascular Access Blood Flow}

\section{Válek', F. Lopot', S. Dusilová Sulková ${ }^{2}$ \\ ${ }^{1}$ Int. odd. Strahov, 1. LF UK, VFN, Prague; ${ }^{2}$ KGM, LF UK a FN, Hradec Kralové}

Introduction: Vascular access blood flow measurement (QVA) is considered an optimal method of vascular access monitoring, because it allows early detection of stenosis. According to K/DOQI recommendations, it is advisable to indicate fistulography when blood flow decreases by $25 \%$ compared with previous period. However, it can be presumed that blood flow fluctuates even in vascular accesses without stenosis. The aim of the study is the assessment of physiological fluctuations of arteriovenous fistula (AVF) blood flow and objective determination of blood flow changes range on this basis and determination, at which blood flow decrement to intervene. Methods: Patients in chronic hemodialysis treatment, dialysed at least 24 months via native fistula without the necessity of radiointervention or surgery were included in the study. The group consisted of 34 persons (out of them $23.5 \%$ with the diagnosis of diabetes mellitus, median age was 64.5 years, median length of hemodialysis treatment 56 months; median of follow-up 41 months. Repeated measurements of vascular access blood flow using termodilution method (monitor BTM, Fresenius) were performed. The number of measurements in one patients was 8 to 30 (median 15). Variation coefficient of blood flow was counted from individual values in every patient. Results: Mean QVA during the study period was $885 \pm 333 \mathrm{ml} / \mathrm{min}$ (median $837 \mathrm{ml} / \mathrm{min}$ ), mean variation coefficient of the entire group $21.6 \pm 11.7 \%$ (range $3.7-62.7 \%$ ). Variation coefficient of the BTM module measurement was $6 \%$. This means that the variation coefficient of QVA itself was $20.7 \%$. Conclusion: The results have shown that nativ vascular fistula blood flow fluctuates significantly. The recommended limit of blood flow decrement of $25 \%$ according to $\mathrm{K} / \mathrm{DOQI}$ is according to our results on the margin of physiological variability.

\section{5}

\section{The Influence of Intravenous Iron (Feiv) on Oxidation Stress in Hemodialysed Patients (HD) in Different Levels of Vitamin C}

\author{
J. Eiselt' ${ }^{1}$ J. Racek ${ }^{2}$, K. Opatrný Jr. ${ }^{1}$, L. Trefil ${ }^{2}$, P. Stehlík ${ }^{2}$ \\ ${ }^{1} 1$ st Medical Department, Medical Faculty and Faculty \\ Hospital, ${ }^{2}$ Institute of Clinical Biochemistry, Plzeň
}

Introduction: The decline of vitamin C (C) level in HD impairs antioxidation defence, however, $\mathrm{C}$ can have a prooxidation effect by reducing $\mathrm{Fe}$ (III) to $\mathrm{Fe}(\mathrm{II})$ and production of hydroxyl radical. We investigated whether oxidation stress induced by Feiv is different in HD patients with low and physiological level of $\mathrm{C}$ and if i.v. administration $\mathrm{C}$ (Civ) during HD changes the Feiv response. Methods: $20 \mathrm{HD}$ persons with $\mathrm{C}$ deficiency $[15.7(8.0-22.7) \mu \mathrm{mol} / 1$ and 20 controls [55.3 (45.2-80.4), $\mathrm{p}<0.001]$ were given an infusion of $100 \mathrm{mg}$ Fe saccharate in 150 to $180 \mathrm{~min}$ of 4-hour HD treatment (low $\mathrm{C}+$ Feiv protocol). After 4 weeks of p.o. supplementation patients had $\mathrm{C}$ levels comparable to controls and were administered 4 types of treatment: 1 / Feiv as at the study introduction; $2 /$ Feiv $+\mathrm{Civ}(\mathrm{C} 2 \mathrm{mg} / \mathrm{min}$ during the entire of HD); 3/ normal saline (NS); 4/ NS + Civ. Barbituric acid reacting substances (TBARS), transferrin saturation (TSAT), serum C level and glutathion (GSH) in erythrocytes were investigated. Samples were collected before HD, before and in the middle and after Feiv (NS) and 15, 30 and 60 min after infusion. The calculated values were medians (interquartile ranges), statistical comparison was performed using Wilcoxon test. Results: Fe induced comparable increase of TBARS in C deficiency [before Feiv 1.9 (1.4-1.9), after Feiv $2.6(2.3-2.9) \mu \mathrm{mol} / 1, \mathrm{p}<0.01]$ and after normalization of $\mathrm{C}$ by its p.o. supplementation 1.9 (1.7-2.1) and 2.6 (2.5-2.9), $\mathrm{p}<0.01$. In Feiv $+\mathrm{Civ}$ there was higher increase of 
TBARS at the end of the infusion $3.1(2.8-3.2)$ than in Feiv administration only $(\mathrm{p}<0.01)$. Also after 15,30 and 60 min after Feiv there were higher TBARS concentrations in Feiv $+\mathrm{Civ}$ protocol than in Feiv protocol. TSAT increased in all Feivs, it did not change in NS and NS + Civ. GSH was not influenced by any protocol. Conclusion: Normal dose of ferrum saccharate increases oxidation stress in HD patients. It develops extracelularly both in C deficiency and physiological levels. In simultaneous administration of ferrum saccharate and vitamin $\mathrm{C}$, prooxidation effect of vitamin $\mathrm{C}$ is obvious. Therefore we consider this combination as inadvisable.

\section{6 \\ Urea Distribution Volume (UDV) in Obese Dialysed Females - Comparison of Anthropometric Formula with Dialysate Urea Output Calculation}

\author{
P. Knetl, J. Toč́k, M. Winkler \\ Medical Department, Dialysis Unit, Jihlava
}

Introduction: Direct assessment of dialysis dose (PDD) depends significantly on UDV value. The aim of the study is to determine, whether unexpectedly low KT/V in PDD in obese females is not caused by overestimation of UDV when using Watson formula. Methods: Continual collection of used dialysate via modified infusion pump was performed twice in 2 patients with BMI of 43 and 65 and the amount of removed urea was calculated. UDV was calculated as UDV (litres) $=\left(\mathrm{A}-\mathrm{UF} \times \mathrm{C}_{0}\right) /\left(\mathrm{C}_{0}-\mathrm{C}_{\text {ekv }}\right)$, where $\mathrm{A}=$ the amount of removed urea, UF ultrafiltration during $\mathrm{HD}$ in litres, $\mathrm{C}_{0}$ serum urea before HD. Equilibrated urea concentration in blood $\left(\mathrm{C}_{\text {ekv }}\right)$ was estimated from $\mathrm{C}_{\mathrm{ekv}}=\mathrm{C}_{0}-\left(\mathrm{A}-\mathrm{C}_{0} \times \mathrm{UF}\right) / \mathrm{V}$, where for $\mathrm{V}$ the estimate of UDV from formula No. (1) was used, where urea after dialysis was used instead $\mathrm{C}_{\text {ekv }}$. Results: UDV value in litres according to Watson was 57.2 in the first patient and the mean from the 2 measurements was 58.8, these values of the second patient were 52.3 and 45.7, respectively. KT/V calculated from Daugirdas equation using values from individual measurements and using equlibrated urea level were $1.05,1.15 ; 0.95,1.02$. Conclusion: 1 . The error in estimation of UDV using Watson formula does not completely explain the difficult achievement of KT/V with direct assessment of dialysis dose. 2 . Assessment of UDV via urea output depends very significantly on $\mathrm{C}_{\text {ekv }}$. When more accurate result is needed, than probably the direct measurement from blood collected $30 \mathrm{~min}$ after dialysis has to be performed. The same applies to KT/V calculation from Daugirdas formula, where the use of non-equilibrated urea level may lead to undertreatment. 3. measurement of urea output via continuous collection of dialysate is simple and together with direct quantification of dialysis effectivity is a very useful tool for adequate dialysis dose specification.
07

\section{Alterations of Uromodulin Biology - A Common Denominator of the Genetically Heterogeneous FJHN/MCKD Syndrome}

\author{
P. Vyleťal', M. Kublová1, V. Barešová1, M. Kalbacová1, \\ K. Hodanová1, J. Majewski², A. Simmonds ${ }^{3}$ \\ G. Venkat-Raman ${ }^{4}$, M. Elleder ${ }^{1}$, S. Kmoch ${ }^{1}$ \\ 1ÚDMP, 1. LF UK, Prague; ${ }^{2}$ Genome Quebec Innovation \\ Center, Montreal; 3Purine Res. Lab., Guy's Hospital, London; \\ ${ }^{4}$ Queen Alexandra Hospital, Potsmouth
}

Introduction: Autosomal dominant hyperuricemia, gout, renal cysts and progressive renal insufficiency are hallmarks of a disease complex comprising familial juvenile uremic nephropathy (FJHN), medullary cystic disease type 1 (MCKD1) and type 2 (MCKD2). In some families the disease is associated with mutations of the gene encoding for uromodulin (UMOD). In other families, the disease genes are not yet known and the link between the genetic heterogeneity and mechanisms leading to the common phenotype symptoms is not clear. Methods: We investigated relevant biochemical parameters in 27 FJHN/MCKD families, performed the whole genome mapping and linkage analysis to search for FJHN/MCKD loci, analysed UMOD gene, characterised mutant UMOD proteins and performed immunohistochemical and electronoptical investigation in kidney tissues. We defined two candidate disease regions on chromosomes $16 \mathrm{p} 11.2$ and 1q41, proved genetic heterogeneity of FJHD/MCKD and defined basic pathogenic mechanisms associated with identified UMOD mutations. Results: We found that reduction in urinary UMOD excretion is a common feature shared by almost all of the families independently of their linkage groups but this was associated with significant case specific differences in the UMOD histochemical staining patterns in kidney. Conclusion: Our results show that several genetic defects interfere with UMOD biology, which lead to the development of the common FJHN/MCKD phenotype and suggest that 'uromodulin associated kidney diseases' (UAKD) may be a more appropriate term for the FJHN/MCKD syndrome. Urinary UMOD testing is a best method for identification of additional UAKD families and linkage mapping is a tool to reveal still unknown UAKD genes. Their identification may help to clarify the exact biological roles of UMOD, to provide better diagnostic techniques and to suggest potential therapeutic targets and approaches.

\section{8}

\section{Nuclear Factor Kappa B and Its Relation to Diabetic Nephropathy}

\author{
M. Romžová1, K. Kološtová2 ${ }^{2}$ D. Hohenadeß ${ }^{\beta}$, M. Fojtiková4, \\ M. Cerná1, I. Rychlík ${ }^{5}$ \\ 'Department of Cellular and Molecular Biology, 3rd Medical \\ Faculty, Charles University, ${ }^{2}$ Department of Tumor Biology, \\ 3rd Medical Faculty, Charles University, Prague; ${ }^{35}$ th \\ Department Medicine, University Clinic, Mannheim; ${ }^{4}$ Institute \\ of Rheumatology, ${ }^{5}$ nd Department of Medicine, FNKV, Prague
}

Introduction: In diabetic nephropathy (DN), which is the main cause of renal failure in patients with diabetes, individual genetic 
predisposition is presumed. Transcription factor NFKB and its inhibitor I $\mathrm{K}$ could play an important role in the origin and development of diabetic microvascular complications. Methods: 249 diabetic patients type 2 , divided according to renal involvement to diabetics with DN, without DN or with other renal disease (NDRD) and 159 controls were tested for NFBIA and NFkB1 gene polymorphisms (genes coding NFкB and $\mathrm{I} \kappa \mathrm{B}$ ). Additionally 152 patients with systemic lupus erythematosus were tested for NFkBIA polymorphism. Results: We did not find any significant difference of $\mathrm{NF \kappa B1}$ polymorphism between controls and diabetics. We found significant differences in the frequency of NFкBIA genotypes. We observed increased incidence of AA genotype in all diabetic groups vs. controls, especially in diabetics without DN $(p=0.0015)$. The incidence of AG heterozygotes was significantly decreased in NDRD patients $(p=0.0003)$. We did not observe any differences in SLE patients vs. controls. Conclusion: In spite of the fact that we did not confirm any association of $\mathrm{NF} \kappa \mathrm{B}$ with diabetic nephropathy, in the case of NFKBIA polymorphism we found an increased frequency of AA genotype in all groups of diabetics, which renders this genotype risky for this disease. The specificity of the relation of $\mathrm{NF \kappa B}$ to type 2 diabetes is underlined also by the fact, that in SLE, as autoimmune inflammatory disease, where the role of $\mathrm{NF \kappa B}$ in its pathogenesis is presumed, we did not find any association. While in type 2 diabetics without microvascular complications the GG phenotype is protective, in type 2 patients with atherosclerotic vascular changes, i.e. in NDRD patients we detected the AG genotype as protective. This means that $\mathrm{NF} \kappa \mathrm{B}$ probably contributes to the development of diabetes in a different way as in its complications.

\section{9}

\section{New Alternatives for the Treatment of ANCA-Associated Vasculitides}

\author{
R. Ryšavá1, Z. Vaňková1, D. Maixnerová1, E. Jančová1, \\ M. Merta ${ }^{1}$, I. Rychlik², V. Tesaŕ ${ }^{1}$ \\ ${ }^{1} 1$ st Department of Nephrology, 1st Medical Faculty, \\ Charles University, ${ }^{2}$ 2nd Medical Department FNKV, Prague
}

Introduction: ANCA (anti-neutrophil cytoplasmic antibody) associated vasculitides (AAV) comprise a group of life-threatening diseases, which left untreated have a mortality up to $85 \%$ in the first 2 years from the diagnosis. Standard treatment with steroids and cyclophosphamide (CFA) remains very effective even nowadays, in spite of its numerous side-effects. However, it is necessary to treat patients with refractory forms of the disease more and more frequently. Methods: Patients with persistent AAV activity (BVAS: mean and median 10.5) or repeated relapses of the disease were treated with other immunosuppressant than CFA either because of high cumulative CFA dose (mean $37.8 \mathrm{~g}$, median $24 \mathrm{~g}$ ) or its inefficiency. In total, we treated 11 patients $(9$ males/ 2 females; mean age 49 years, 9 Wegener's granulomatosis, 2 microscopic polyangiitis). Four out of them were treated with several therapeutic regimens. In six patients we administered gusperimus in the dose of $0.5 \mathrm{mg} / \mathrm{kg}$ s.c., 21 days of application followed by at least 7 days without treatment for 6 months. Etoposid was given in 6 patients in the dose of $50 \mathrm{mg} 2$ times a week depending on leukocyte count. Infliximab was given in 2 patients in the dose of $6 \mathrm{mg} / \mathrm{kg}$ i.v. in $0,2,6,10$ th weeks and then in 6-week intervals for one year. Rituximab appears to be the most promising treatment, we have used it in 3 patients in the dose of $1 \mathrm{~g}$ i.v. two weeks apart (twice in total) with concomitant application of CFA. Results: Partial remission of the disease (reduction of lung infiltrates, decrease of ANCA antibody titres, decrease of BVAS, normalisation of urine finding) were achieved in 9 patients, in the remaining two the disease was stabilized. Conclusion: Recently there has been a growing number of patients with AAV treated by combined immunosupression who require a non-standard therapy. When all available drugs are used, in most of the patients improvement or stabilization of their condition can be achieved.

Supported by grant IGA NR/8116-3.

\section{0 \\ The Utilization of Rituximab in the Treatment of Renal Diseases - First Experience}

\author{
Z. Vaňková1,2, H. Marečková2, E. Jančová1, R. Ryšavá1, \\ M. Merta ${ }^{1}$ V. Tesař \\ ${ }^{1}$ Department of Nephrology, General Faculty Hospital and \\ 1st Medical Faculty, Charles University, ${ }^{2}$ UIM, General \\ Faculty Hospital and 1st Medical Faculty, Charles \\ University, Prague
}

Introduction: ANCA- associated vasculitis (AAV) and systemic lupus erythematosus (SLE) are severe diseases, in the pathogenesis of which dysbalance of B-lymphocytes plays a significant role. A promising effect of rituximab (anti-CD 20 monoclonal antibody) was proven in clinical studies of treatment of patients with refractory forms of both AAV and SLE but also with rheumatoid arthritis, polymyositis or B-non-Hodgkin lymphopma (B-NHL) associated with cryoglobulinaemia and HCV infection. Methods: Rituximab has been administered to 8 patients in our department up to now -3 patients with AAV ( 2 males, one female, mean age 39.3 years, all diagnosed with Wegener's granulomatosis), 2 patients with SLE (1 male, 1 female, 33 years), 2 patients with B-NHL, cryoglobulinaemia and $\mathrm{HCV}$ infection ( 1 male, 1 female, 41.5 years) and 1 female with membranous nephropathy (MGN) with SLE trait (39 years). The underlying disease was active in all patients (including renal activity) before administration of rituximab and refractory to standard therapy. Clinical and laboratory parameters including B-lymphocyte count were monitored in all patients. Results: In all patients, a prompt decrease of B-lymphocytes to zero values was observed after rituximab administration, and this continues after the termination of the therapy (in one female with SLE patient followed for the longest period of 16 months there has not been a rise in B-lymphocytes after 16 months). At least partial clinical effect (improvement of urinary findings, renal function or systemic symptoms, reduction of pulmonary infiltrates, decrease of antibody titre) was observed in all treated patients, the only exception being the female with MGN, where the B-lymphocyte count recovered the fastest. We have not observed any other side effects of the therapy. Conclusion: Rituximab appears a new promising and at the same time well tolerated alternative in the treatment of renal diseases. We have proven its positive effect in patients with AAV, SLE and cryoglobulinemia in HCV infection in our department. 
011

\section{Children in the Czech Renal Biopsy Registry - 10 years of Experience}

A. Kolský1,2, I. Rychlík1, E. Jančová1, J. Dušek1, M. Hladik1,

S. Skalová1, Z. Pellantová1, P. Geier', J. Skibbová1, M. Kolská1

${ }^{1}$ Czech Registry of Renal Biopsies, ${ }^{2}$ Paediatric

Department, Faculty Thomayer Hospital, Prague

Introduction: The study presents the results of the Czech Registry of Renal Biopsies (CRRB). It comprises a set of 1,434 renal biopsies (RB) performed in children and minors up to 18 years in the years 1994-2003. CRRB comprises almost all RB of native kidneys, which were performed in 10 pediatric centres in our country. Results: The mean age was $12.6 \pm 4.5$ years $(2.5$ months -18 years $), 55.9 \%$ boys, $44.1 \%$ girls. Children $<5$ years were $9.5 \%$, children $5-10$ years were $21.3 \%, 10-15$ years were $35.8 \%$ and $15-18$ were $33.6 \%$. Primary glomerulonephritis (GN) $(65.3 \%)$ and secondary GN $(25.7 \%)$ were the most frequent. The most frequent primary GN was IgA nephropathy $(24.1 \%)$ and minimal change nephrotic syndrome $(10.9 \%)$. Most frequent secondary GN were: thin membrane syndrome $(12.3 \%)$, Alport syndrome (4.6\%), lupus nephritis $(4 \%)$, and Henoch-Schoenlein purpura $(2.8 \%)$. Out of all RB microscopic hematuria (HU) was present in $60 \%$, macroscopic $\mathrm{HU}$ in $14.7 \%$ and proteinuria in $65 \%(22.6 \%$ were $>3.5 \mathrm{~g} / 24 \mathrm{~h}) .12 \%$ patients suffered from hypertension with significantly higher proteinuria and serum creatinine level (s-cr) in $73.2 \%$. When comparing adolescents (15-18 years) vs. all children ( 2.5 months -15 years), $16 \%$ of adolescents were hypertensive, but only $10 \%$ of children $(\mathrm{p}<0.01)$, proteinuria/ $24 \mathrm{~h}$ was $2.1 \pm 3.5$ vs. $2.2 \pm 3.5$ g (n.s.), s-cr $73.8 \pm 69.6$ vs. $105.2 \pm 107.6 \mu \mathrm{mol} / 1(\mathrm{p}<0.01) .78 \% \mathrm{RB}$ were performed under ultrasound control, biopsy gun was used in $26 \%$. Clinically significant complications were present in $3.4 \%$ of patients. Conclusion: CRRB renders important information about epidemiology, indications and opportunities of collaboration in GN in our country.

Supported by the Czech Society of Nephrology.

\section{2}

\section{The Study of Protein Changes in Renal Diseases with Nephrotic Syndrome}

\section{Vojtová1, T. Zima', V. Tesař², M. Kazderová2 \\ ${ }^{1}$ UKBLD, General Faculty Hospital and 1st Medical Faculty, ${ }^{2}$ Department of Nephrology, General Faculty Hospital and 1st Medical Faculty, Prague}

Introduction: Proteinuria is caused by increased permeability of glomerular basal membrane, membrane or podocyte damage, and deterioration of secretory-reabsorptive tubular mechanisms. The exact composition of modified or degraded proteins in proteinurias has not been known yet, but their possible toxic effect on tubular cells and disease progression is presumed. We analysed urinary proteins in patients with nephrotic syndrome using the method of 2D electrophoresis. Methods: We studied the influence of albumin removal on the analysis of the sample and the effect of proteases in the urine.
We tested 20 samples of urine of patients with nephrotic syndrome and other nephropathies (AL amyloidosis, Wegener's granulomatosis). Proteins were first divided according to their isoelectric points by the method of isoelectric focusation on polyacrylamide strips with immobilized linear gradient of $\mathrm{pH} 3-10$ and subsequently they were separated by SDS elecrophoresis in $12 \%$ polyacrylamid gel according to molecular weight. The visualisation was performed with silver. After removal of albumin, lucidity of the whole spectre increases and discrimination of proteins $>30 \mathrm{kDa}$ was more distinctive. Results: By comparing individual protein maps of tested samples it became obvious that a significant proteolysis presenting with increased amount of proteins in the $10 \mathrm{kDa}$ area and decrement of proteins in the $50 \mathrm{kDA}$ area took place without presence of protease inhibitors. The method of 2D electrophoresis was optimalized for samples of patients with nephrotic syndrome. Conclusion: We found that removal of albumin through the use of ammonium sulphate increased lucidity of protein spectres and that proteases probably play a role in the degradation of proteins by tubular mechanisms.

\section{3}

\section{Study of Cytokines and Regulatory Molecules in ANCA-Associated Vasculitis}

\author{
Z. Vaňková1,2, Z. Řihová1, H. Marečková2, E. Jančová1, \\ R. Ryšavá1, J. Závada', M. Merta', V. Tesař \\ ${ }^{1}$ Department of Nephrology, General Faculty Hospital and \\ 1st Medical Faculty, Charles University, ${ }^{2}$ UIM, General \\ Faculty Hospital and 1st Medical Faculty, Charles \\ University, Prague
}

Introduction: ANCA-associated vasculitis (AAV) is an autoimmune disease characterized by necrotizing inflammatory involvement of small arteries, in the pathogenesis of which efectory mechanisms of both humoral and cell-mediated immunity take part. The aim of the study was to assess in a complex way the cell mediated immunological response in a group of patients with AAV of different stages. Methods: We investigated 94 samples of peripheral blood from 69 patients with AAV (42 anti-PR3 positive, 27 anti-MPO positive; 39 Wegener's granulomatosis (WG), 19 microscopic polyangiitis (MPA), 9 renal limited vasculitis (RLV) and 2 Churg-Strauss syndrome (CSS); 51 investigations during remission, 43 during the activity of the disease) and 32 healthy individuals. We investigated constitutional and activational lymphocyte surface molecules, chemokine receptor expression, and intracellular cytokine production. Results: Patients with AAV showed an increased production of interferon gamma (IFN $\gamma$ ) and increased expression of surface molecules CDR5, CD30, CRTH2, HLA-DR, CD80 and CD86 comparing with healthy controls $(p<0.02)$. In anti-PR3 positive patients lower expression of CXCR3 and higher expression of CD30 on CD4 positive lymphocytes compared with anti-MPO3 positive patients were observed $(p=0.03)$. Production of IL2 and CCR5 was lower in patients with WG and MPA than in patients with RLV $(p<0.05)$. Conclusion: Our results confirm the activation of the immune system and $T$ lymphocytes in patients with AAV. Different results in patients anti-PR3 and anti-MPO positive show a different regulation of immune response, where antiPR3 positive patients and also patients with generalised form of the disease have a shift of immune response to TH2 type. 
014

\section{The Results of Mutation Analysis of the Bartter and Gittelman Syndromes in the Czech Republic}

\author{
R. Ryšavá1, M. Urbanová2, J. Štekrová ${ }^{2}$ J. Reiterová1, \\ M. Merta ${ }^{1}$, V. Tesař ${ }^{1}$, O. Schück ${ }^{3}$, L. Podracká ${ }^{4}$ \\ ${ }^{1}$ Department of Nephrology, General Faculty Hospital and \\ 1st Medical Faculty, Charles University, ${ }^{2}$ Institute for \\ Biology and Human genetics, ${ }^{3}$ Department of Nephrology, \\ IKEM, Prague; ${ }^{4} 1 \mathrm{st}$ Department of Children and \\ Adolescents, Pavlov Josef Safarik University, Košice
}

Introduction: The aim of our grant project is to prove the genetic basis of Bartter (BS) and Gitelman (GS) syndromes in patients with clinical suspicion of these hereditary nephropathies in the Czech Republic and in Slovakia. Both syndromes present with metabolic alkalosis, hypokalemia, and hypotension, while the difference are observed in serum magnesium concentration and in calciuria. In BS impairment of several tubular transports (most often $\mathrm{Na}-\mathrm{K}-2 \mathrm{Cl}$ or $\mathrm{CIC}-\mathrm{Kb}$ ) in the ascending limb of the loop of Henle may be present, in GS the defect is on the level of $\mathrm{Na}-\mathrm{Cl}$ cotrasporter in the distal tubule. Methods: 27 out of 38 patients with clinical suspicion of BS or GS were selected and blood samples for DNA separation were collected. By use of SSCP and later by direct detection with sequenation we investigated first the gene for GS (SLC12A3). We focused on changes in the exon parts of the gene (26 exons), where most of upto-now published mutations are located. Results: We found specific mutations in 12 out of 15 unrelated individuals. Most of them have been already described, but 2 of them are new, yet unpublished. These are the 238 ins.CC(pPro79fsX35) in 2 related patients and 480 ins. C(pPro160fsX97) mutations. Both are shift mutations, where the final protein is reduced to $11 \%$ (the first case) and $25 \%$ (the second one) of the total length. This defective protein is then the cause of malfunction of thiazide-sensitive transporter (Na-Cl-cotransporter). Conclusion: The results of our investigation point to frequent capture of genetic basis of GS in our patients. Two new mutations in SLC12A3 gene are priority observations. At the moment we concentrate on the mutation analysis in the patients with suspicion of BS

Supported by grants IGA NR/8116-3 and VZ MS 0021620806.

\section{5 \\ Renal Damage as a Consequence of Ethyleneglycol Intoxication}

\section{Křenová, D. Peclová \\ Toxicological Information Centre, Prague}

Introduction: Ethyleneglycol (EG) is one of the most nephrotoxic substances. The aim of the study was the analysis of EG intoxications in Czech Republic in the years 2000-2004. Methods: The Request files of the Toxicology Information Centre and databases of toxicological laboratories were searched for EG intoxication cases. The course of intoxication was determined from hospital reports. When serum creatinine concentration (S-cr) at discharge was higher than $110 \mu \mathrm{mol} / \mathrm{l}$, nephrological follow-up was adviced. Results: 206 discharge reports were collected. In 131 patients only mild metabolic acidosis was present, 24 adults died. Crystals of calcium oxalate mainly in proximal tubules were found by kidney histology in 5 patients out of 8 necropsy protocols. In 51 patients S-cr was higher than $110 \mu \mathrm{mol} / \mathrm{l}$ during hospitalisation. The mean peak S-cr was $443 \mu \mathrm{mol} / 1$. In 20 patients renal function normalised before discharge. $\mathrm{S}$-cr remained elevated in 31 patients, out of whom 10 were not interested in further nephrological follow-up. In 10 patients renal function normalised within 6 , in 2 patients within 12 and in 1 patient within 17 months from discharge. In 3 patients S-cr was still elevated after 6 months, but they did not come for further follow-up. In 5 patients renal damage was still present 12 months after discharge (mean S-cr $158 \mu \mathrm{mol} / \mathrm{l}$ ). Median of ingested EG dose was $150 \mathrm{vs.} 88 \mathrm{ml}$, median time elapsed from EG ingestion to treatment was 16 vs. $4 \mathrm{~h}$ and median of serum EG concentration was 1.9 vs. $0.48 \mathrm{~g} / 1$ in patients with elevated S-cr 12 months after discharge compared with patients, whose renal function normalised by this time. Conclusion: Renal damage is influenced by the ingested dose of EG (serum EG concentration) and the time between ingestion and treatment initiation.

\section{6 \\ Peritoneal Transport of Procalcitonin (PCT) and Its Elimination in Peritoneal Dialysis (PD) Patients}

\author{
S. Opatrná1, J. Klaboch 1 , H. Šlajsová', I. Holubec², \\ F. Šefrna', O. Topolčan ${ }^{2}$, K. Opatrný Jr. ${ }^{1}$ \\ ${ }^{1} 1$ st Medical Department, Faculty Hospital, ${ }^{2}$ 2nd Medical \\ Department, Faculty Hospital, Plzeň
}

Introduction: Plasma concentration of PCT (molecular weight $13 \mathrm{kDA}$ ), a new inflammation and/or infection marker, is increased in PD patients. PCT can be detected in dialysate. The aim of this study was to assess: (1) the proportion of peritoneal $(\mathrm{pCl})$ and renal $(\mathrm{rCl})$ clearance on PCT elimination and (2) to elucidate the origin of PCT in the dialysate. Methods: 13 patients with chronic renal failure treated by PD ( 9 males, mean age 59.8 years, mean treatment duration 28 months) were investigated. The total weekly creatinine clearance $(\mathrm{ClCr})$, total weekly $\mathrm{Kt} / \mathrm{V}$, residual glomerular filtration and PCT clearance were assessed from $24 \mathrm{~h}$ urine and dialysate collections. PCT and $\alpha_{2}$-microglobulin $\left(\alpha_{2} \mathrm{M}\right.$, molecular weight $11.8 \mathrm{kDa}$, entering the dialysate exclusively from systemic circulation), were assessed in the dialysate after 10-hour night exchange and at 0 and 4-hour time of peritoneal equilibration test. Results: $\mathrm{pCl}$ of PCT was $1.56 \mathrm{ml} / \mathrm{min}$ and correlated with the volume of dialysate in $24 \mathrm{~h}$ (Sperman test, $\mathrm{r}=0.65, \mathrm{p}<0.05$ ), $\mathrm{rCl}$ PCT was $1.01 \mathrm{ml} / \mathrm{min}$ and correlated with $\mathrm{ClCr}(\mathrm{r}=0.72, \mathrm{p}<0.01)$; correlation with residual glomerular filtration almost reached statistical significance $(\mathrm{r}=0.59$, $\mathrm{p}=0.051)$. The increase of PCT and $\alpha_{2} \mathrm{M}$ correlated both in $0-10 \mathrm{~h}$ interval $(r=0.92, p<0.001)$ and in $4-10 \mathrm{~h}$ interval $(\mathrm{r}=0.89$, $\mathrm{p}<0.001$ ). A significant correlation was found also between PCT and $\alpha_{2} \mathrm{M}$ concentrations ratio in dialysate and plasma after $10 \mathrm{~h}$ exchange $(\mathrm{r}=0.78, \mathrm{p}<0.01)$. Conclusion: Both peritoneal dialysis and residual renal function contributes to the elimination of PCT in PD patients. Similar characteristics of peritoneal transport of PTC and $\alpha_{2} \mathrm{M}$ bring indirect evidence that PCT enters dialysate from 
systemic circulation. The presence of PCT in the dialysate is probably not a consequence of its peritoneal production.

\section{7 \\ Fluid Transport Pathways and their Determinants in PD Patients with Ultrafiltration Failure}

\author{
A. Pariková1, W. Smit ${ }^{2}$, D. Struijk ${ }^{2,3}$, R. Krediet ${ }^{3}$ \\ ${ }^{1}$ Department of Nephrology, General Faculty Hospital and \\ 1st Medical Faculty, Charles University, Prague; ${ }^{2}$ Dianet \\ Foundation, ${ }^{3}$ Academic Medical Center UvA, Amsterdam
}

Introduction: Ultrafiltration failure (UFF) is a serious complication of peritoneal dialysis. An impairment of free water transport (FTW) is its frequent cause in long-term PD patients. The aim of the study was to analyse changes in water transport and their determinants in UFF patients over the time of PD. Methods: Standard peritoneal permeability analyses of 50 stable PD patients with UFF were analysed. Fluid transport through small pores (SPT), FWT at 60 minutes and their determinants (ultrafiltration coefficient LpA, reflection coefficient and osmotic conductance to glucose) were assessed. Patients were divided in group I treated less than 24 months, group II treated 24-60 months and group III treated more than 60 months. Results: Transcapillary ultrafiltration, SPT and FWT were significantly lower in group III. The osmotic conductance to glucose and ultrafiltration coefficient LpA was significantly lower in groups III. A positive relationship was present between FWT and the duration of PD in UFF less than 2 years $(\mathrm{p}<0.01)$. FWT was positively related to the osmotic conductance in all groups. In groups I and II it also correlated with the reflection and ultrafiltration coefficient. Conclusion: The patterns of ultrafiltration failure in peritoneal dialysis patients depend on the duration of treatment. An impaired free water transport in UFF patients associated with a decreased osmotic conductance to glucose might be due to a decreased reflection coefficient. In long-term UFF patients a reduced ultrafiltration coefficient LpA contributes to this phenomenon.

\section{8}

\section{Soluble Receptor for Advanced Glycation Products in Patients with Impaired Renal Function}

\author{
M. Kalousová1, M. Hodková2,3, M. Kazderová2, J. Fialová2, \\ V. Tesař², S. Dusilová Sulková3,4, T. Zima ${ }^{1}$ \\ ${ }^{1}$ UKBLD 1st Medical Faculty and General Faculty Hospital, \\ Charles University, ${ }^{2}$ Department of Nephrology, \\ ${ }^{3}$ Strahov Medical Department, Prague; ${ }^{4} \mathrm{KGM}$, Medical \\ Faculty and Faculty Hospital, Hradec Kralové
}

Introduction: Advanced glycation products (AGEs) accumulate in patients with impaired renal function and they belong to uremic toxins. Some of their pathological effects are mediated by RAGE receptor (receptor for AGEs). Soluble RAGE (sRAGE) is a naturally present inhibitor of AGE-RAGE interaction. The aim of the study was to describe the relation of sRAGE to renal function and dialysis methods. Methods: The investigated group comprised of 25 patients with various degree of renal insufficiency, 20 chronic hemodialysis (HD) patients, 15 patients treated by peritoneal dialysis (PD) and 21 controls. sRAGE was assessed immunochemically (ELISA) and routine biochemistry parameters were measured using accredited methods. Results: sRAGE correlates positively with serum creatinine concentration $(r=5 \%, p<0.05)$ and its relation to creatinine clearance is hyperbolic. sRAGE is significantly increased mainly in patients with terminal renal failure $(3119.0 \pm 968.4 \mathrm{pg} / \mathrm{ml}$ in $\mathrm{HD}$ and $3652.7 \pm 1677.7 \mathrm{pg} / \mathrm{ml}$ in PD vs. $1405.1 \pm 426.1 \mathrm{pg} / \mathrm{ml}$ in controls, $\mathrm{p}<0.001$ vs. controls). sRAGE can be detected in used dialysate in PD patients (median $75.8 \mathrm{pg} / \mathrm{ml}$ ), correlates with serum concentration $(\mathrm{r}=0.67, \mathrm{p}<0.05)$ and is related to protein dialysate loss. In HD patients sRAGE increases by $50 \%(\mathrm{p}<0.001)$ from 0 to $15 \mathrm{~min}$ during dialysis and hemofiltration and decreases from then to the end of the procedure. Conclusion: Serum concentration of sRAGE is increased in patients with impaired renal function, mainly in patients with terminal renal failure. The question remains, whether this is an epiphenomenon accompanying decreased renal function or an upregulation to protect against toxic effects of AGEs.

Supported by grant IGA MZ CR NR/8094-3.

\section{9}

Acid-Base Balance in Chronic Renal Failure

P. Hrabčaková', M. Mydlik², K. Derzsiová ${ }^{3}$

${ }^{1}$ VSOUG SL n.o., Kosice, Slovakia; ${ }^{2}$ Department of

Nephrology, Medical Faculty, Pavol Jozef Safarik University,

Bratislava; ${ }^{3}$ Nephrological Longman Centre, Ltd., Košice

Introduction: Metabolic acidosis is present in patients with chronic renal failure. Methods: We investigated the state of acidbase balance $(A B B)$ in haemodialysis treated patients $(n=20)$ before and after two consecutive haemodialysis sessions and in the interdialysis period in two parts of the project and assessed the relation between $\mathrm{ABB}$ and interdialysis weight gain $(\mathrm{n}=16)$. Parameters of $\mathrm{ABB}$ were investigated in 12 continual ambulatory peritoneal dialysis patients using peritoneal dialysate solutions with different concentrations of glucose and circadian rhythm of ABB in 11 CAPD patients in other two parts of the project. Results: We confirmed in the first part of the study that bicarbonate dialysis with bicarbonate concentration of $34 \mathrm{mmol} / 1$ in dialysis solution, taking $4 \mathrm{~h} 3$ times a week ensures $\mathrm{pH}$ in normal range in patients with chronic renal failure even in the interdialysis period. We did not confirm statistically significant effect of interdialysis weight gain on $\mathrm{pH}$ and bicarbonate concentration in blood. We did not find any statistically significant difference of ABB between the group of diabetics and patients without diabetes treated by CAPD. The investigation of circadian rhythm of ABB during CAPD proved that this treatment resulted in continuous metabolic acidosis normalisation in chronic uraemic patients. 
020

\section{Higher Intrarenal Expression of TGF- $\beta 1$ in Early Acute Humoral Rejection of Kidney Graft}

P. Hřibová1, K. Bartošová2 , J. Slatinská2, K. Hyklová1, I. Brabcová1, H. Volk³ O. Viklický1,2

${ }^{1}$ Transplant Laboratory, IKEM, ${ }^{2}$ Department of Nephrology, IKEM, Prague; ${ }^{3}$ Institute of Medical Immunology, Charité, Berlin

Introduction: Acute humoral rejection represents a rare but clinically serious complication after renal transplantation. Immunological mechanisms of early acute cellular rejection (ACR) and early acute humoral rejection (AHR) may differ. The aim of our study was to assess whether there is a different profile of intrarenal gene expression in ACR and AHR. Methods: All patients who received kidney transplant in the period between October 2002 and September 2005 and who had their first early ( $9 \pm 4$ postoperative day) biopsy proven rejection $(n=65)$ were enrolled. Intrarenal mRNA expression of cytokines and chemokines TGF- $\beta 1$, TNF- $\alpha$, MCP- 1 and RANTES using real-time RT-PCR was assessed in biopsy specimens. MannWhitney test was used for the comparison between the groups. Results: 22 biopsies were diagnosed as AHR ( 5 with ATN and 7 in combination with ACR) and remaining 43 as ACR [including borderline changes $(n=14)$ ]. ACR was accompanied by significantly higher RANTES mRNA expression than AHR $(\mathrm{p}<0.05)$. Isolated ACR was accompanied with higher expression of MCP-1 and RANTES chemokines $(p<0.05)$ than combined acute cellular and humoral rejection. On the contrary, isolated AHR was accompanied by significantly higher TGF- $\beta 1$ expression than AHR combined with ACR or ATN $(p<0.01)$ and also than combined acute humoral and cellular rejection $(\mathrm{p}<0.05)$. Conclusion: Chemokines have probably a limited role in the pathogenesis of early AHR compared with ACR. Higher expression of TGF- $\beta 1$ mRNA in renal grafts with early AGR may explain worse outcome of these grafts.

Supported by grant IGA MZ CR No. NR/8897-4/2006.

021

Immunosupression with Triple Combination with Tacrolimus With or Without Monoclonal Antibody Induction: A Multicentric Randomized Study in Children After Kidney Transplantation

K. Vondrák1, R. Grenda ${ }^{2}$, A. Watson ${ }^{3}$, J. Janda1, E. Šimková1, T. Seeman', J. Dušek', J. Kreisinger ${ }^{1}$, P. Dvořák ${ }^{1}$

${ }^{1}$ Department of Pediatrics, Motol Faculty Hospital, Prague; ${ }^{2}$ Children's Memor. Health Inst., Warszaw; ${ }^{3}$ Children Kidney Unit, Nottingham

15 European centres took part in a 6 months study comparing a protocol with tacrolimus with and without basiliximab induction in children with kidney graft. Patients were randomized to groups with tacrolimus(tac)/azathioprine(aza)/steroids(st) (controls) or with tac/aza/st with basiliximab (bas). The first dose of (bas) was administered during $4 \mathrm{~h}$ before reperfusion, the second on the 4 th day. The target tac blood level in 0-21 days was 15 (range 10-20 ng/ml) and subsequently $10(5-15 \mathrm{ng} / \mathrm{ml})$. Methylprednisolone in the dose of $300-600 \mathrm{mg} / \mathrm{ml}$ i.v. was given on day 0 , then the dose was tapered significantly in both groups to $\leq 10 \mathrm{mg} / \mathrm{ml}$ since the 43rd day after transplantation. Results: 93 (control) and 99 (bas) children were analysed, the mean age was 11.3 and 11.7 years (range 2-17), mean MHC mismatch was 2.3 (control) and 2.5 (bas). $81.7 \%$ (control) and $88-89 \%$ (bas) completed the study, none of them died. 5 grafts were lost in control and 4 in (bas) group. The incidence of bioptically proven acute rejections (BPAR) was $20.4 \%$ (control) and $19.2 \%$ (bas), corticoresistant AR were $3.2 \%$, respectively $3.0 \%$. In both groups combined the incidence of BPAR was 26.9 in children $\geq 12$ years $(\mathrm{n}=104)$ and $11.4 \%$ in children $<12$ years $(\mathrm{n}=88)(\mathrm{p}=0.007$ chisquare). The most frequent side effects were hypertension $(38.7 \%$; $34.3 \%)$, renal function impairment $(29.0 \%$; $30.3 \%)$, UTI $(28.0 \%$; $19.2 \%)$, and nephrotoxicity $(4.3 \% ; 14.3 \%)$. The incidence of viral infections was $16.1 \%$ (controls) and $15.2 \%$ (bas). Two cases of PDLD occurred in control group. The incidence of diabetes was $4.3 \%$ (controls) and 5.1\% (bas). Mean serum creatinine concentration was 86 , respectively $91 \mu \mathrm{mol} / \mathrm{l}$. Calculated GFR was 79.4 and $77.6 \mathrm{ml} / \mathrm{min} /$ $1.73 \mathrm{~m}$. Conclusion: The induction by basixilimab in triple combination with tacrolimus after kidney transplantation was safe, but did not improve treatment efficacy in the studied population. Renal functions were comparatively good in both groups.

Supported by Research project FNM 00064203/6906.

\section{2 \\ Polymorphism of the Hemoxygenase 1 T(-413)A Gene Influences the Incidence of Acute Rejections and Kidney Transplants Survival \\ O. Viklický1, J. Hubáček1, I. Brabcová1, P. Hřibová1, K. Bartošová1, S. Vitko', H. Volk ${ }^{2}$ \\ ${ }^{1}$ IKEM, Prague; ${ }^{2}$ Charité-University Medicine, Berlin}

Introduction: Hemoxygenase is considered to be a protective factor, which protects transplanted kidney from ischemia/reperfusion and immunological injury. Methods: In this association study, we investigated a newly described HO-1 T(-413)A polymorphism in 226 pairs of donors and recipients of transplanted cadaverous kidneys, who underwent surgery in 2000-2003, using RFLP-PCR. Univariant and multivariant statistical analyses were performed to elucidate the relationship of the polymorphism to the incidence of acute tubular necrosis (ATN), acute rejection (AR), chronic transplant nephropathy $(\mathrm{CTN})$ and graft function failure. Results: Recipients homozygous for -413 AA were significantly more frequently represented among the patients, who had a functioning graft at the end of follow-up period compared with those, whose graft function failed (38.8 vs. $18.8 \%, \mathrm{p}<0.01)$ and they had lower risk of graft loss compared with patients with -413 AT + TT genotypes (OR: 0.36, CI: 0.17-0.80, $\mathrm{p}<0.05$ ). These patients had lower risk of acute rejection (OR: 0.40 , CI: $0.21-0.75, p<0.01)$ compared with other genotypes of -413 $\mathrm{AT}+\mathrm{TT}$ as well. We did not find any relation between recipient 
genotype and ATN or CTN. There was no correlation between gene variants of donors and AR, ATN, CTN or graft failure. However, we found that homozygous TT recipients, to whom kidney from homozygous AA donors was transplanted, were at higher risk of graft function loss $(\mathrm{p}<0.05)$ and of acute rejection $(\mathrm{p}<0.05)$. Recipients with AA genotype who received a kidney from TT donor were most frequently represented among patients with a functioning graft $(p<0.05)$. Conclusions: Recipients of kidney graft with high production of hemoxygenase ( $-413 \mathrm{AA})$ are at low risk of graft function loss due to immunological causes and can thus be treaded with less aggressive and less toxic therapy.

\section{3 \\ Ciprophloxacin Prophylaxis is Related to Higher Incidence of Diarrhoea in Patients after Kidney Transplantation}

\author{
L. Lyerová1, V. Lánská1, V. Teplan', Š. Vitko², O. Viklický1 \\ ${ }^{1}$ Department of Nephrology, IKEM, ${ }^{2}$ Transplant Centre \\ IKEM, Prague
}

Introduction: Diarrhoea represents a frequent complication in patients after kidney transplantation (TPL), the ethiopathogenesis of which is multifactorial. The aim of this study was to describe the effect of two short-term antibiotic prophylactic regimens after TPL. Methods: Effect of short-term (3-5 days) intravenous prophylaxis with ciprophloxaxin (CIP, $n=108$ ) or cefuroxim (CRX, $n=84)$ on diarrhoea and other complications incidence in consecutive transplanted patients in 2004-2005 was analysed in this open-label study. The basic immunosuppressive therapy consisted of tacrolimus (induction level $10-20 \mathrm{ng} / \mathrm{ml})$, mycophenolate mofetil ( $2 \mathrm{~g} /$ day $)$ and prednisone $(20 \mathrm{mg} /$ day $)$. The follow-up period was three months. Univariant and multivariant analysis was used to assess risk factors of complication development. Results: Incidence of urinary tract infections was the same in CIP and CRX groups (28 vs. $26 \%$, n.s.). Likewise, incidence of pneumonia ( 5 vs. $2 \%$, n.s.) and surgical wound infection (13 vs. 13\%, n.s.) was comparable. The incidence of acute pyelonephritis was higher in CIP group compared with CRX (16 vs. $6 \%, \mathrm{p}<0.05)$. Diarrhoea in the first week after transplantation was significantly more frequent in CIP group (43 vs. $12 \%, \mathrm{p}<0.001$ ). Univariant analysis revealed the duration of dialysis treatment before transplantation as a risk factor for the incidence of early post transplantation diarrhoea $(1,081$ vs. 775 days, $\mathrm{p}<0.03)$ and similarly also ciprofloxacine prophylaxis. Risk of diarrhoea was nor related to stool cultivation results, presence of diabetes mellitus, delayed graft function or tacrolimus concentration. Multivariant analysis then confirmed that the use of short-term CIP prophylaxis represents more than five time higher risk of diarrhoea in the first days after transplantation (OR: 5.4, CI: 2.49-11.9, p < 0.01). Conclusion: Ciprofloxacin is not a suitable prophylactic antibiotic in patients after renal transplantation because of increased risk of diarrhoea.
024

\section{Activity and Expression of Mitogen Activated Protein Kinase (MAPK) p38 in Early and Advanced Stages of Diabetic Nephropathy (DN)}

\author{
R. Komers ${ }^{1,2}$, J. Lindley², T. Oyama², S. Anderson ${ }^{2}$ \\ ${ }^{1}$ Centre of Diabetology, IKEM, Prague; ${ }^{2}$ Division of \\ Nephrology, OHSU, Portland, USA
}

Introduction: Diabetes is linked to activation of p38 MAPK in the kidney. Because of processes, in which it is involved (pro-growth signalisation, oxidative stress, inflammatory signalisation, and vasoconstriction), it is presumed that this leads to morphological and functional changes in the kidney. Present pieces of knowledge show that renal activation of p38 is characteristic for early stages of DN. However, activity of $\mathrm{p} 38$ in advanced DN with proteinuria and glomerulosclerosis (GS) has not been studied. Methods: Streptozotocin diabetic rats $(\mathrm{DM}, 60 \mathrm{mg} / \mathrm{kg}$ bwt) were studied for 4 weeks $(\mathrm{n}=8)$ and 12 months $(\mathrm{n}=4)$ after diabetes induction. DM were treated with sub-optimal insulin dose/2-4U/day) to achieve a moderately severe glycaemia and compared with non-diabetic animals of the same age (C). Renal activity of p38 was assessed by in vitro kinase assay with ATF-2 substrate and by expression of phosphorylated (active) and total p38 (P-p38, t-p38, western blotting). Renal localization of p38 was studied immunohistochemically. Results: p38 (kinase assay) and P-p38 expression, as well as the P-p38/t-p38 ratio were elevated in DM compared to $\mathrm{C}(+81 \%,+70 \%$ and $40 \%$, $\mathrm{p}<0.05$ vs. C). P-p38 was found in macula densa cells (MD) in DM and C. DM had also positivity in adjacent parts of distal nephron (DT) and in glomeruli. DM developed proteinuria and GS after 12 months. p38 activity and P-p38 expression were similarly increased as in early stages $(79 \%$ respectively $60 \%, \mathrm{p}<0.01$ vs. C). Nevertheless, only tubular but not glomerular distribution of P-p38 was observed at this stage. Conclusions: Renal activity of p38 is increased in early and in advanced stages of experimental DN. Active p38 is localized mainly in MD and DT during the entire disease course, while glomerular expression is the feature of early DN.

R.K. supported by grant MZO-00023001.

025

Aluminium Concentration in Dialysed Patients in the Czech Republic in the Years 2001-2005

\author{
P. Buček¹, K. Lach², M. Goluchová1, V. Mrózek ${ }^{1}$ \\ ${ }^{1}$ Dialysis centre, Hospital in Frýdek-Mistek, Frýdek Mistek; \\ ${ }^{2}$ Analytical laboratories OKD DPB, Paskov
}

Introduction: The authors submit a review of aluminium (Al) concentrations in dialysed patients in the Czech Republic during last five years. Clinical signs of $\mathrm{Al}$ intoxication are not a significant problem at present, but still we can encounter patients with increased Al concentration. Al has no physiological function in humans, its concentration in healthy individuals is less than $2.2 \mu \mathrm{g} / \mathrm{l}$. Increased Al concentration in dialysed patients is influenced mainly by the quality 
of treated water. Serum Al concentrations up to $30 \mu \mathrm{g} / 1$ are considered acceptable. Higher concentrations can adversely influence metabolic processes mainly in bone and bone marrow. Al concentration higher than $100 \mu \mathrm{g} / 1$ is unambiguously toxic. Method: Blood sample is collected to special test-tubes after Desferoxamin application of $5 / \mathrm{mg}$ $\mathrm{kg}$ usually during previous dialysis session. Serum samples are sterilised by radiation and $\mathrm{Al}$ concentration analysis is performed in the analytical laboratory OKD DBP in Paskov using atomic absorption spectrophotometer. Investigations performed in the years 2001-2005 are presented in this study. Results: 1 . The number of tests in 2001-5 ranged from 975 to 1,189 per year. 2. the number of centres sending sera for investigation fluctuated from 19 to 14 per year. 3. 12 dialysis centres performed Al concentration test every year in the years 2001-2005. 4. Mean AL concentration in investigated patients decreases gradually from $30 \mu \mathrm{g} / 1$ in 2001 to $18 \mu \mathrm{g} / \mathrm{l}$ in 2005 . 5. Mean concentration higher than $30 \mu \mathrm{g} / 1$ was present in 3 dialysis centres in 2005. Conclusion: 1 . Al concentration analysis is not regularly performed in most $\mathrm{HD}$ centres. 2. Mean $\mathrm{Al}$ concentration in dialysis patients decreases. 3. At present, we only occasionally encounter patients with unequivocally toxic $\mathrm{Al}$ concentration over $100 \mu \mathrm{g} / \mathrm{l}$. In 2005 eight those patients were found. 4. Al concentration analysis is available and paid by health care insurance companies. 


\section{Poster Presentations}

P26

\section{Thrombogenicity of Polyacrylnitril Dialysis Membrane AN69ST}

P. Richtrová ${ }^{1}$, K.Opatrný Jr. ${ }^{1}$, F. Šefrna ${ }^{1}$, I. Vit ${ }^{1}$, R. Perlik ${ }^{2}$

${ }^{1} 1$ st Medical Department, Medical Faculty and Faculty

Hospital, ${ }^{2}$ UKHB, Medical Faculty and Faculty Hospital, Plzeň

Introduction: Thrombogenicity of dialysis membranes is an important criterion of biocompatibility. Polyacrylnitril membrane AN69ST has a polyethylenimine coated surface. This surface modification enables heparin adsorption and thus lower thrombogenicity of the membrane is presumed. We compared the thrombogenicity of AN69ST membrane under the condition of two different rinsings of extracorporeal circuit (EC). Methods: 10 chronically hemodialysed (HD) patients, median aged 72 years (51-79), were investigated during hemodialysis with AN69ST membrane under the condition of EC rinse with normal saline (NS) without heparin and NS with nonfractioned heparin (UFH) in the concentration of 5,000 IU/1. Plasma concentrations of trombin-antitrombin III (TATIII) complexes, heparin (antiXa UFH) and aPTT were assessed before HD and in 15th, 60th and 240th min of treatment. UFH was used for systemic anticoagulation. Results: TATIII increased during HD after NS without UFH rinse $(0.0 \mu \mathrm{g} / 1,0.0-17.0$ before HD vs. $0.0,0.0-4.1$ in the 15 th $\mathrm{min}$ ) and this increase reached statistical significance in the 60th $\min (2.9,0.9-23.6, \mathrm{p}<0.01)$ and in 240th $\min (36.9,18.5-60.6$, $\mathrm{p}<0.01$, paired Wilcoxon). Under the conditions of NS with UFH rinse concentration of TATIII increased as well $(0.0 \mu \mathrm{g} / 1,0.0-12.0$ before vs. $0.0,0.0-4.1$ in 15 th $\min$ and $1.0,0.0-5.0$ in 60 th $\mathrm{min}$ ) and reached statistical significance in the 240th min (20.2, 3.0-62.2, $\mathrm{p}<0.01$, paired Wilcoxon). When comparing the changes during HD between both rinses, significant difference of earlier and more pronounced increase of TATIII in rinse without UFH $(\mathrm{p}<0.05$, paired Wilcoxon) becomes apparent. We found significantly lower antigay after rinse without UHF in 15th, 60th and 240th min and significantly shorter aPTT in 60th min (everything $\mathrm{p}<0.05$, paired Wilcoxon). Conclusion: The preparation of extracorporeal circuit with the AN69ST membrane by rinsing it with NS and UFH leads according to plasma TATIII concentrations to decrease of its thrombogenicity.
P27

The Influence of Endothelin ET-A Receptor Polymorphism on the Progression of Autosomal Dominant Polycystic Kidney Disease

\author{
J. Reiterová', M. Merta1, D. Maixnerová', H. Obeidová1, \\ J. Štekrová2, V. Tesaŕ \\ 1Department of Nephrology, 1st Medical Faculty, Charles \\ University, ${ }^{2}$ Institute of Medical Genetics, 1st Medical \\ Faculty, Charles University, Prague
}

Introduction: Polycystic kidney disease of autosomal dominant type (PKDAD) is a disease with a significant intrafamiliar variability. Entothelin-1 is a vasoconstriction factor, whose effect is mediated after binding to two types of receptors ET-A and ET-B. Vasoconstriction is mediated mainly by ET-A receptors in vascular smooth muscle cells. We investigated the importance of $1363 \mathrm{C} / \mathrm{T}$ polymorphism in exon 8 of ETA receptor because of $\mathrm{T}$ allele of this polymorphism was found significantly more frequently in hypertensives with higher pulsatile component of blood pressure. Methods: We investigated 193 patients (pts) (106 females, 87 males) with PKDAD and renal failure (ESRD). Patients were divided into 3 groups: (1) 47 pts with ESRD developed later than 63 years of age (slow progressors), (2) 49 pts with ESRD before 45 years of age (rapid progressors) and (3) 97 pts with ESRD between 45 and 63 years of age. Other 63 healthy individuals ( 30 men, 33 women, mean age $51.4 \pm 8.2$ years) were analysed as control group. DNA samples were amplified with PCR with described primers and then sequenced. We compared the distribution of genotypes among groups and time of ESRD according to different genotypes. Results: The distribution of $\mathrm{C} / \mathrm{T}$ genotypes did not differ statistically among groups (slow progressors: CC 15/47, CT 27/47, TT 5/47, rapid progressors. CC 9/49, CT 32/49, TT 8/49, ESRD 45-63 years: CC 20/97, CT 56/97, TT 21/97, control group: CC 19/63, CT 35/63, TT 9/63. CC genotype was non-significantly more frequent in slow progressors. When comparing ages of ESRD, in women with CC genotype had ESRD significantly later than with CT genotype: CC $57.4 \pm 8$ years, CT $53.0 \pm 9.1$ years and TT $54.5 \pm 6.4$ years (t-test, $\mathrm{p}=0.018$ ). Conclusion: $\mathrm{CC}$ genotype which is connected with lower pulse pressure probably favourably influences prognosis of females with PKDAD.

Supported by investigation project MSMT 0021620806.

Introduction: ADPKD is the most common hereditary renal disease. The disease is caused by mutations of PKD1 (affecting roughly $85 \%$ of ADPKD patients) and PKD2 (14\% of ADPKD patients) genes. 
PKD1 locus (MIM 601313) was linked to the short arm of chromosome 16, at 16p13.3 and so far 266 different germline mutations have been reported. PKD2 locus (MIM 173910) was localized to 4q 13-23 and 72 different germline mutations were identified. Patients with PKD2 mutation have milder clinical course (later onset of the disease and it complication) in comparison with PKD1 patients. Methods: DNA presymptomatic diagnosis is performed in our laboratory using highly polymorphic microsatellite markers for DNA linkage analysis. Presymptomatic DNA diagnosis was performed in 250 unrelated ADPKD families. The direct detection of mutations in the non-duplicated region of the PKD1 gene was performed in 90 nonrelated individuals.

Results: the disease was clearly linked to PKD1 gene in 32 families and in 58 patients with end stage renal failure earlier than 50 years. We detected 19 mutations in 21 families/individuals and 16 mutations unique for Czech population. Conclusion: Establishment of localization and type of mutations and their genotype-phenotype correlation in ADPKD families will improve DNA diagnosis and could help to assess the clinical prognosis of ADPKD patients.

Supported by the project VZ MSMT 0021620806. 


\section{Kidney \\ Blood Pressure Research}

Anderson, S. O24

Barešová, V. O7

Bartošová, K. O20, O22

Brabcová, I. O20, O22

Buček, P. O25

Bürgelová, M. O1

Černá, M. O8

Červenka, L. O1

Derzsiová, K. O19

Dušek, J. O11, O21

Dusilová Sulková, S. O4, O18

Dvořák, P. O21

Eiselt, J. O5

Elleder, M. O7

Ferda, J. O3

Fialová, J. O18

Fojtiková, M. O8

Geier, P. O11

Goluchová, M. O25

Grenda, R. O21

Hladik, M. O11

Hodanová, K. O7

Hodková, M. O18

Hohenadel, D. O8

Holubec, I. O16

Hrabčaková, P. O19

Hřibová, P. O20, O22

Hubáček, J. O22
Hyklová, K. O20

Jančová, E. O9, O10, O11, O13

Janda, J. O21

Kalbacová, M. O7

Kalousová, M. O18

Kazderová, M. O12, 018

Klaboch, J. O16

Kmoch, S. O7

Knetl, P. O6

Kohoutová, M. P28

Kološtová, K. O8

Kolská, M. O11

Kolský, A. O11

Komers, R. O2, O24

Kopkan, L. O1

Krediet, R. O17

Kreisinger, J. O21

Křenová, M. O15

Kreuzberg, B. O3

Kublová, M. 07

Lach, K. O25

Lánská, V. O23

Lecian, D. O2

Lindley, J. O24

Lodererová, A. O2

Lopot, F. O4

Lyerová, L. O23

Maixnerová, D. O9, P27

Majewski, J. O7

Marečková, H. O10, O13

Mareš, J. O3
Merta, M. O9, O10, O13, O14, P27, P28

Mrózek, V. O25

Mydlik, M. O19

Obeidová, H. P27

Ohlídalová, K. O3

Opatrná, S. O3, O16

Opatrný, K. Jr. ${ }^{\dagger}$ O3, O5, O16, P26

Oyama, T. O24

Pařiková, A. O17

Peclová, D. O15

Pellantová, Z. O11

Perlik, R. P26

Podracká, L. O14

Racek, J. O5

Reiterová, J. O14, P27, P28

Richtrová, P. P26

Řihová, Z. O13

Romžová, M. O8

Rychlík, I. O8, O9, O11

Ryšavá, R. O9, O10, O13, O14

Schück, O. O14

Seeman, T. O21

Šefrna, F. O16, P26

Šimková, E. O21

Simmonds, A. O7

Skálová, S. O11

Skibbová, J. O11

Šlajsová, H. O16

Slatinská, J. O20
Smit, W. O17

Stehlík, P. O5

Štekrová, J. O14, P27, P28

Struijk, D. O17

Svobodová, S. P28

Teplan, V. O1, O23

Tesař, V. O9, O10, O12, O13, O14, O18, P27

Thumová, M. O1

Točík, J. O6

Topolčan, O. O16

Trefil, L. O5

Urbanová, M. O14

Válek, M. O4

Vaněčková, I. O1

Vaňková, Z. O9, O10, O13

Venkat-Raman, G. O7

Veselá, J. O2

Viklický, O. O20, O22, O23

Vit, I. P26

Vitko, Š. O22, O23

Vojtová, L. O12

Volk, H. O20, O22

Vondrák, K. O21

Vyletal, P. O7

Watson, A. O21

Winkler, M. O6

Závada, J. O13

Ždychová, J. O2

Zima, T. O12, O18

\section{KARGER}

(C) 2006 S. Karger AG, Basel

Fax +4161306 1234

E-Mail karger@karger.ch

www.karger.com

Accessible online at:

www.karger.com/journals/kbr 